\title{
AUTOMATIC CRUDE OIL DILUTION CONTROL WITH PREMIUM OIL SEGREGATION USING NEAR INFRARED (NIR) ON-LINE SYSTEM
}

\section{FATAH YAH ABD MANAF* and ANDREW YAP KIAN CHUNG*}

\begin{abstract}
The clarification operation in a palm oil mill is an important processing step that should be carefully handled with as much care as possible. As the oil loss in the clarification processes is a major source of oil loss in the overall milling operation, there is an urgent need to improve the crude oil dilution control for efficient oil recovery. Currently, there are no reliable methods to maintain the oil to crude oil ratio. As a result, no automatic dilution control is in practice even when mill throughputs are widely fluctuating. The trend to produce crude palm oil with low $(<1.5 \%)$ free fatty acid (FFA) appears to be increasing among the millers as it commands a premium price in the world markets. In order to meet this demand, it will be worthwhile to use the near infrared (NIR) analyser for rapid analysis of the crude oil. It is also more efficient than the conventional method. Field trial results have shown that the NIR On-line system can be used not only to control the water dilution at an average of $39 \%$ to $40 \%$ of the crude oil but also to monitor the FFA content below $1.5 \%$ for automatic premium oil segregation during the palm oil processing.
\end{abstract}

\section{Keywords: near infrared (NIR), crude oil dilution, automatic control, premium oil, FFA.}

Date received: 9 August 2017; Sent for revision: 16 August 2017; Received in final form: 24 October 2017; Accepted: 26 January 2018.

\section{INTRODUCTION}

The milling technology related to crude oil dilution control has not made any significant advances in the last 30 years. As the palm oil production has grown rapidly in recent years it is time the milling operation also considers the introduction of an automatic system into the process line. Having accurate, current and real time data on process parameters and correcting them to achieve the optimum values would enhance the efficiency in the process operation. The aim of this study is to establish a control system for water dilution and segregate crude palm oil based on free fatty acid (FFA) content.

\footnotetext{
Malaysian Palm Oil Board,

6 Persiaran Institusi,

43000 Kajang, Selangor, Malaysia.

E-mail: fatahyah@mpob.gov.my
}

\section{AUTOMATIC CRUDE OIL DILUTION CONTROL}

The crude palm oil (CPO) released by the twin screw presses is a mixture about $55 \%$ oil, $35 \%$ water and about $10 \%$ solids (Maycock, 1987). Its inability to flow in the oil gutter has made it necessary for it to be diluted with water with the approximate volume being $40 \%$ of the crude oil. After dilution, the desired ratios of the crude oil components would be about 39\% oil, $54 \%$ water and $7 \%$ solids (Mongana Report, 1955). If the press throughputs are consistent the dilution control may be maintained at the desired ratios without any issues by diluting a fixed amount of water flowing through a weir. But unfortunately the number of presses in operation at any point in time cannot be fixed as it is dependent on many factors like the need to stop a press when the digester level drops below three-quarter full. In such cases the water dilution valve has to be 
regulated to adjust the new flow requirement. If the operators are watchful and are alert all the time this operation can be performed with acceptable results but as this is not often possible when manually done and the resulting deviation of the component ratios are known to affect the separation efficiency of the clarifier. The manual operation relies on a sample being taken and subjected to manual centrifuging to decide on the volume of water needed to correct the component ratios. The delay and the estimated volume of water dilution is a non-scientific process operation compared to a proper automatic dilution system. For good clarifier performance the component ratios should not fluctuate widely and in order to ensure it, this automatic dilution control system using the latest near infrared (NIR) analyser is expected to perform more efficiently with the result that the clarifier will give the perfect output.

The clarification process itself is a time-honored density-based separation system that is simple and reliable but for continuous operation, as is the case with palm oil milling operation, the flow into and out of the clarifier must necessarily be continuous. The oil rising to the top of the clarifier is skimmed off gently from the top layer of oil that is approximately $150 \mathrm{~mm}$ thick and is channelled to the pure oil tank (Menon, 2008). The sludge riser pipe is connected approximately three-quarter from the top of the clarifier. Running by the side of the clarifier, it is connected to a square chamber at the top for the sludge or heavy phase to rise and be discharged into a pipe flowing into a sludge tank. The fluctuation of oil band thickness can affect the sensitive oil separation process at the skimmer level especially if the oil layer is too thin. The right dilution will ensure a uniform oil band in the clarifier. In addition, it will ensure consistent waste water to fresh fruit bunch (FFB) ratio.

Overdilution not only results in producing the obvious excess waste water but it also results in the little-known increase in the absolute oil loss in waste water. This is because the oil loss in the sludge separator is fixed at about $4 \%$ to sample irrespective of the \% dilution (Menon, 2009). In mathematical terms, it can be illustrated as shown below, taking into account that machine constant is not affected by dilution rate.

Assuming that the waste water is 5000 litres at normal dilution.

Absolute oil loss based on $4 \%$ on sample $=200$ litres.

If this waste water is diluted $100 \%$ so that the waste water is 10000 litres.

Absolute oil loss based on $4 \%$ d on sample $=400$ litres.

This illustrates that higher dilution will promote absolute oil losses.

Table 1 shows the comparison with good and poor dilution by actual trial.

Currently, manual control oil dilution is based on the water content as established by hand centrifuging samples at $1 \mathrm{hr}$ intervals, which are generally not followed by millers due to the difficulty in controlling the water added to the press juice. In conventional oil room operation, the mills calibrate the weirs through which the optimum amount of water is fed into the oil gutter situated beneath the presses. The calibrations are set to cater for the numbers of presses in operation at any one time, and the operator is supposed to adjusts the dilution water valve to control the water flow rate into the oil gutter (Lim and Whiting, 1976).

Dilution rate would differ from mill to mill and even at the same mill it will fluctuate depending on the weather (rainfall or dry season), planting materials and FFB quality. This is especially so when the number of presses in operation vary with the availability of digested fruits for pressing. Nicholas and Tiong (1988) after their investigation suggested that by using manual dilution control, the average

TABLE 1. COMPARISON WITHIN DILUTION RATE

\begin{tabular}{|c|c|c|}
\hline Good dilution rate & Low dilution rate & High dilution rate \\
\hline $\begin{array}{l}\text { Oil will flow smoothly at oil } \\
\text { gutter and sand trap tank. }\end{array}$ & $\begin{array}{l}\text { Oil layer too thick could increase } \\
\text { oil loss in underflow. }\end{array}$ & $\begin{array}{l}\text { Thin oil layer, sludge may } \\
\text { flow into pure oil tank. }\end{array}$ \\
\hline $\begin{array}{l}\text { Able to see oil cell size of } 50 \\
\text { sen coin floating to top surface } \\
\text { at sand trap tank. }\end{array}$ & $\begin{array}{l}\text { Only fine oil cell will float and level } \\
\text { of sand trap tank will increase due } \\
\text { to increase of viscosity. }\end{array}$ & $\begin{array}{l}\text { Sign of emulsification at top } \\
\text { surface of the sand trap tank. }\end{array}$ \\
\hline $\begin{array}{l}\text { Smooth distribution of screen } \\
\text { waste at vibrating screen mesh. }\end{array}$ & $\begin{array}{l}\text { Most of the screen waste will } \\
\text { accumulate at middle of vibrating } \\
\text { screen and will cause overloading } \\
\text { at screen mesh. }\end{array}$ & $\begin{array}{l}\text { Screen waste will travel fast on } \\
\text { screen mash and inlet feed } \\
\text { will look watery. }\end{array}$ \\
\hline $\begin{array}{l}\text { Good separation and clarifier } \\
\text { tank with low oil loss at sludge } \\
\text { underflow. }\end{array}$ & $\begin{array}{l}\text { Will cause high oil loss at clarifier } \\
\text { underflow. Low moisture content } \\
\text { but high NOS. }\end{array}$ & $\begin{array}{l}\text { Will also cause high oil loss at } \\
\text { clarifier underflow, emulsification } \\
\text { sign on top of oil surface, high } \\
\text { moisture content but low NOS. }\end{array}$ \\
\hline
\end{tabular}

Note: NOS - non-oil solid.

Source: Ishwant Singh (2012). 
oil loss in the sludge from the clarification process is about $0.5 \%$ to FFB. With automatic dilution control, the oil loss achievable can be reduced to below $0.45 \%$ to FFB. The increase of total oil losses could rise mainly due to over-dilution; can reduce the retention time for separation leading to poor settling rate. The study also showed that the efficient oil settling rate for crude oil is achieved with approximately $22 \%$ to $35 \%$ of water dilution to diluted crude oil (Stork, 1960).

The automatic NIR control system which interfaces with the computer will perform the computation to determine the correct volume of water required for dilution control. The system was developed for water injection system in its crude oil line to automatically regulate the water content of its crude oil at a pre-set value.

\section{PREMIUM OIL SEGREGATION USING NEAR INFRARED (NIR) ON-LINE SYSTEM}

In line with the increasing market demand for low FFA palm oil, the interest to produce CPO with low $(<1.5 \%)$ FFA has increased among millers as such oil commands a premium price. The FFA content of $\mathrm{CPO}$ is one of the parameters used as an indicator of quality by palm oil refiners (Saad et al., 2006). Premium prices are paid for better quality oils. This preference for low FFA oil has encouraged millers to improve their oil quality leading to the production of a special grade palm oil. Various attempts have been made to achieve that. To date, as a result of intensive research and development activities in the Malaysian palm oil industry, significant progress has been made to develop such premium palm oil with exceptionally low FFA through discipline harvesting practices and prompt processing after harvesting.

CPO generally contains FFA below 5\% (Corley and Tinker, 2003) which needs to be removed as part of the refining process. Thus, the lower content of FFA will result in lower refining losses and lower usage of bleaching earth. The FFA levels differ and vary from the time of harvesting to the milling processing and storage. The handling of the bunch during and after harvesting is important to minimise fruit bruising. To reduce FFA to a minimum, bunches needs to reach the mill and be processed as soon as possible. Lipase activities cause elevated FFA levels in CPO. FFA is formed when the bound fatty acid in the triglyceride molecules is split either by chemical or enzymatic hydrolysis (Abigor et al., 1985; Henderson and Osborne, 1990; Sambanthamurthi et al., 1995; Ngando et al., 2006). FFA increases if there is any delay in processing. There is an adage that says that oil is made in the field and not at the mill which is a reflection of the harvesting standards, FFB ripeness, how the FFB is handled during and after harvesting and the speed the FFB is sent for processing.

Currently, the premium oil at the mill is manually channelled every 30 min after analysing the acid content and switching the flow of CPO into the clarifier tank. The standard practice to determine the FFA content in crude palm oil is the titration method. By using the NIR system, there is a great advantage in that it is more efficient, faster and solvent-free compared to the chemical method. The FFA of the CPO can be analysed instantaneously and conveyed as an electrical signal to operate a two-way valve that switches the CPO flow into separate tanks and automatically segregate the low from the high FFA CPO.

\section{NIR Technology}

The introduction of NIR in the crude oil pipe in a mill shows the obvious advantages of using NIR technology for process control. The increased yield, improved product quality and the lower product testing cost are some of the benefits that the industry has gained from the on-line deployment of the NIR technology (Valarie et al., 1990). In order to achieve high product quality and effective process control, production parameters have to be continuously measured, monitored and controlled during the production process (Selman, 1989; Kellner, 1990). Modern NIR technology relies heavily on the computer to control and acquire data from the instrument and facilitate calibration and data analysis (Burns and Ciurczak, 2008).

The use of NIR waves for the fast analysis of liquids flowing through pipes or open channels is now becoming an increasingly popular method of detection and measurement of moisture. The technology uses the waves in the near-infrared region of the electromagnetic spectrum having wavelengths from about $750 \mathrm{~nm}$ to $2500 \mathrm{~nm}$ which is non-destructive and in this technology no sample preparation is required. If the samples contain such bonds as $\mathrm{CH}, \mathrm{NH}$ or $\mathrm{OH}$ with concentrations exceeding about $0.1 \%$ of the total composition, the results are reliable and acceptable. The determination of FFA in palm oil by NIR is proposed based on the $\mathrm{C}=\mathrm{O}$ stretching bands that lie in the overlap region of the first overtone and the combination region (1850-2050 nm) as presented in Table 2 (Che Man and Moh,1998).

NIR On-line is ideally suited spectroscopic technique for rapid process measurements because of its ability to perform remote measurements via high-efficiency quartz optics. With an available spectrum range of 350 to $1750 \mathrm{~nm}$, the instrument is equipped with a dual light-source, which can perform continuous operation for two years with an automatic internal reference. A Diode Array-based spectrometer is used due to its superior speed of 
TABLE 2. MAJOR ANALYTICAL BANDS AND THEIR RELATIVE PEAK POSITION OF NIR SPECTROSCOPY FROM 1850-2050 nm

\begin{tabular}{lc}
\hline Functional groups & Approximate band position (nm) \\
\hline $\mathrm{RCO}_{2} \mathrm{H}$ & $1880-1900^{\mathrm{a}}$ \\
$\mathrm{H}_{2} \mathrm{O}$ & 1940 \\
$\mathrm{RCO}_{2} \mathrm{R}^{\prime}$ & $1900-1950^{\mathrm{a}}$ \\
$\mathrm{CO}$ & $2020-2050$ \\
\hline
\end{tabular}

Source: aWheeler (1959).

Che Man and Moh (1998).

Note: NIR - near infrared.

measurement and correct measurements of moving samples then allows assessment of average process properties as well as homogeneity.

The NIR calibration model will have a standard error calibration (SEC) that is of the same order of magnitude as the error of the reference method and a correlation coefficient $\mathrm{R}^{2}$ that approaches 1 . A second independent set of samples could be used to validate the performance of the calibration model to ensure that the derived NIR spectroscopic model is both representative and compensates effectively for encountering interfering absorptions and scattering differences. The adequacy of the calibration method is judged based on the correlation coefficient, $R^{2}$, the standard error of prediction (SEP), and the slope and $y$-intercept of the regression line. A robust NIR model usually yields an $R$ and a slope that approaches 1 and a SEP that is similar to the SEC of the derived NIR calibration model.

\section{MATERIALS AND METHODOLOGY}

\section{NIR On-line System}

The NIR On-line system consists of a source, a detector, and a dispersive element to allow the intensity at different wavelengths to be recorded. A Diode Array Device from NIR-Online ${ }^{\circledR}$ with patented construction using light-emitting diodes, LED to offer greater lifetime, spectral stability and reduced power consumption as shown in Figure 1 has been used to determine the oil content of diluted

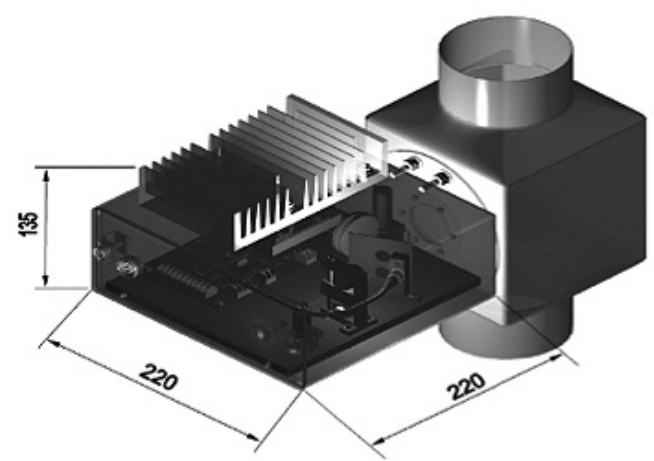

Figure 1. NIR-Online system.
CPO. Colour Camera $80 \mu$ spatial resolution is used to take images of the material and assess its visible properties, which later the colour information of the image is used to determine a chromatic spectrum, resolved into blue, cyan, green, yellow, orange and red.

\section{Control Valve}

The control valve located in the hot water line will regulate hot water flow for dilution water flow.

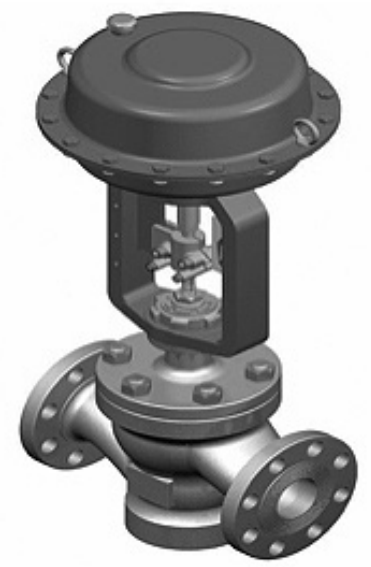

Figure 2. Pneumatic control valve.

\section{Inline Mixer}

The function of the inline mixer is to ensure good mixing of oil and water before passing through the sensor.

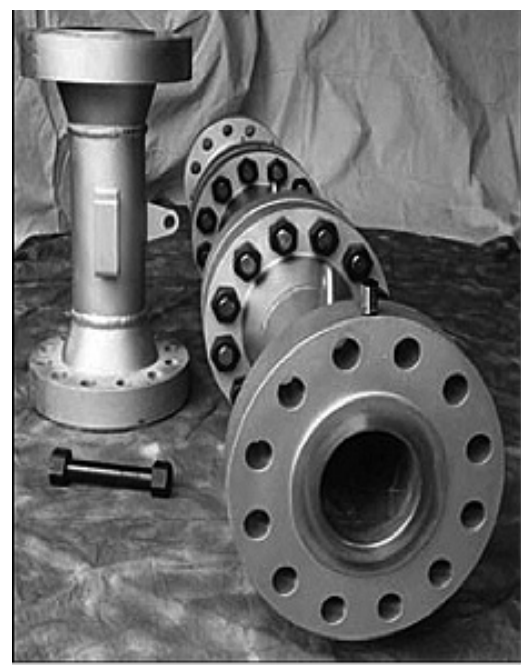

Figure 3. Inline mixer.

Engineering works such as the installation of the valve, inline mixer, piping cables attachment and other equipment have to be integrated with the NIR On-line instrument in the production line for measuring crude oil and FFA content in pressed liquor. 


\section{NIR Calibration}

The system must be calibrated first using a representative of similar samples of the product to be analysed. These are known as the reference values. The values must be obtained by using a standard laboratory method and the calibration between the two methods is established as $\mathrm{R}^{2}$, SEC and SEP of the validation set were obtained for oil, FFA and water.

About 120 samples of the crude oil after press were scanned from 1100 to $2500 \mathrm{~nm}$ in a sample cell using NIR On-line Analyser. Each sampling was performed in duplicate by reloading the sample for duplicate analysis. The respective samples were then analysed in the laboratory according to the $M P O B$ Test Method. The scans were saved and transferred to the software. The partial least squares regression was used to develop the calibration and predicted models between NIR spectra and analytical data obtained by the reference method. Once the calibration models have been developed, they were downloaded into the analyser for use in analysing everyday samples.

\section{Experimental Set Up}

Figure 4 illustrates the automatic system control schematic that is installed before entering the clarifier tank. For automatic control dilution the trial was carried out by flow measurement and ratio control. To achieve this control objective, the measurement process variable is compared to the thermostat set point. The difference between the set point and the measured value constitute the error which is used in a control algorithm such as PD (proportional- derivative) controller to generate an output signal to the final control element (FCE). This automatic control system is supported by a computer which performs an intensive computation to determine the correct volume of water required for dilution control and for monitoring FFA for the premium oil.

\section{Process Description of NIR On-line System on Water Dilution}

A process description of NIR On-line system on water dilution is described below:

- The NIR sensor detects the oil ratio to the crude oil content and sends an analog signal (4-20 $\mathrm{mA})$ to the programmable logic control (PLC) (Figure 4).

- The signal is amplified and interfaced to give an indication on the computer monitor. The detected values are compared against a preset value, and the error values are used for generating analog signals.

- An analog actuates a control valve located on the crude oil line for injecting the appropriate dilution water (Figure 5).

\section{Process Description of NIR On-line System on Premium Oil Segregation}

A process description of NIR on-line system on premium oil segregation is described below:

- The NIR sensor detects the FFA content in CPO and send a signal to PLC.

- The signal is amplified and interfaced to give an indication on the computer monitor and also operate the control valves located on the pipeline in the clarifier tank.

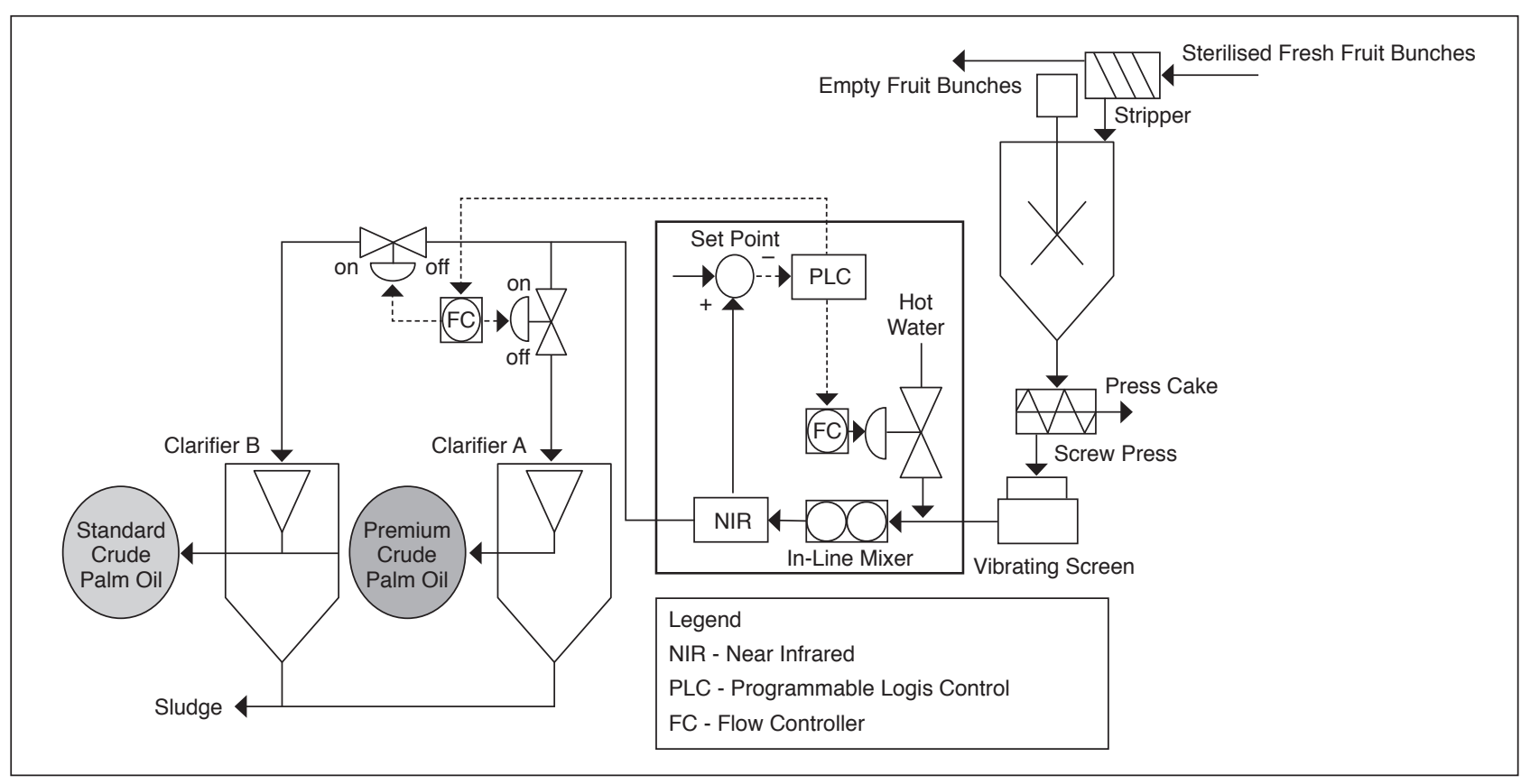

Figure 4. Schematic diagram of automatic crude oil dilution control with premium oil segregation using NIR On-line system. 
- The clarifier valve opening is dependent on the signal given by the controller. The threshold value is set to a maximum of $1.5 \%$ FFA for premium oil (clarifier A) and above $1.51 \%$ FFA for standard quality oil (clarifier B) (Figure 6).

- The system is linked to a computer for continuous monitoring of FFA (Figure 7).

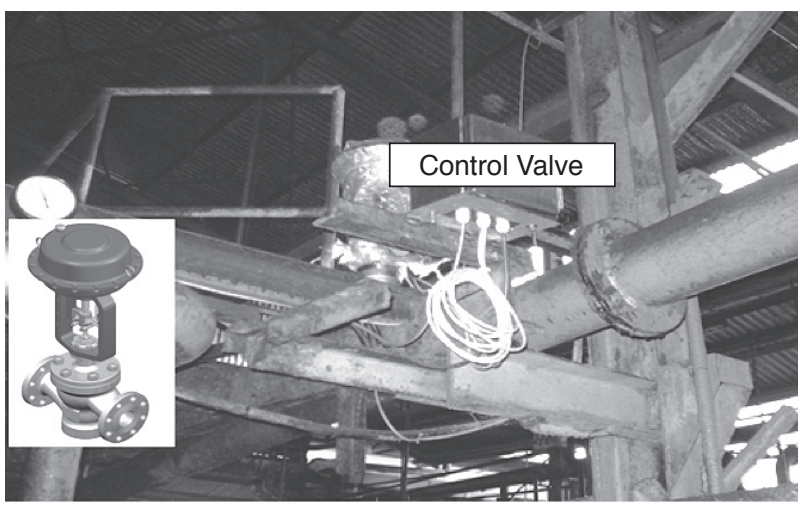

Figure 5. Control valve for maintaining constant water in the crude oil.

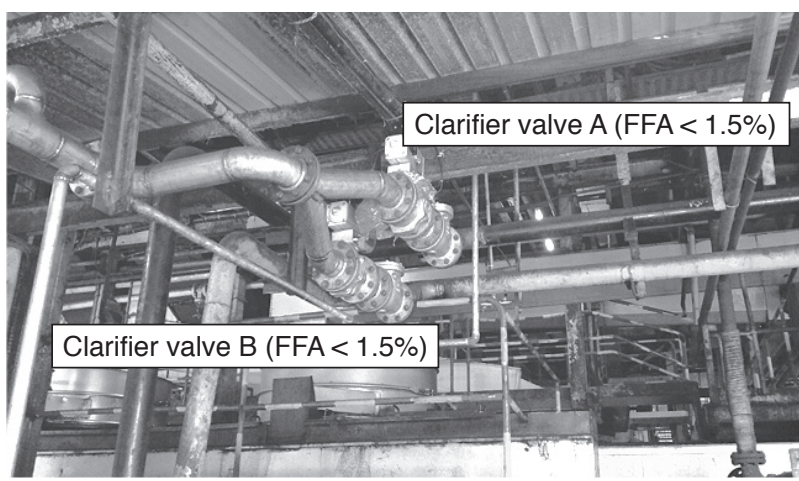

Figure 6. Control valve for clarifier.

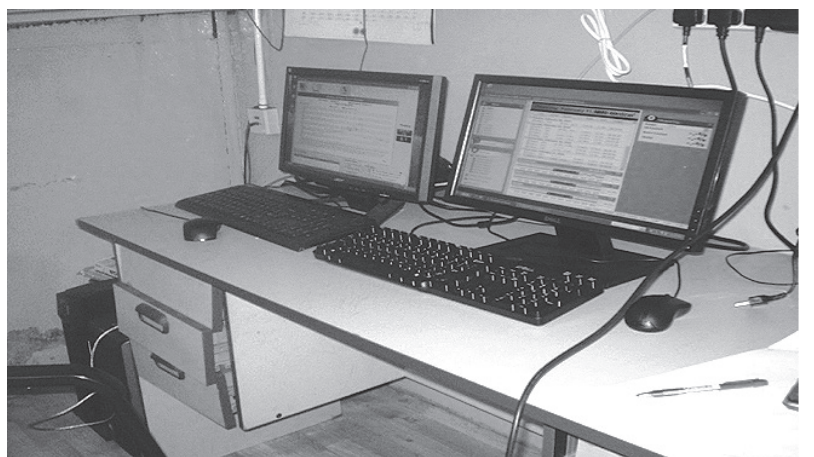

Figure 7. Human machine interface for the system.

\section{RESULTS AND DISCUSSION}

Preliminary analysis showed that the oil content of the press juice ranges from $44 \%$ to $61 \%$, depending on the quality of the fruits (Table 3). Thus, dilution is required to reduce the viscosity of the palm oil after being pressed. By applying the right percentage of dilution it will result in an effective separation during clarification.
TABLE 3. OIL CONTENT AFTER SCREW PRESS

\begin{tabular}{ccc}
\hline Day & $\%$ Oil & $\% \mathbf{H}_{\mathbf{2}} \mathbf{O}$ \\
\hline 1 & 61.05 & 13.19 \\
2 & 51.86 & 26.03 \\
3 & 50.22 & 44.07 \\
4 & 44.07 & 14.58 \\
5 & 48.08 & 32.76 \\
\hline
\end{tabular}

Three NIR calibration models for oil, FFA and moisture content in CPO were duly established as shown in Table 4 and Figures 8, 9 and 10.

Correlation coefficients, SEP and slope values were compared to evaluate which calibrations were most successful. The prediction was also carried out using the external validation set. The correlation coefficient $\left(\mathrm{R}^{2}\right)$ of calibration obtained were $0.881,0947$ and 0.854 for oil, FFA and moisture respectively. Once the calibrations were developed the applicability was confirmed through validation on the calibration. The prediction of validation samples using this calibration model resulted in an $\mathrm{R}^{2}$ value of $0.906,0.898$ and 0.939 for oil, water and FFA, respectively. In this validation, $\mathrm{R}^{2}$ and SEP value were at least equal to or better than that calculated in the calibration. Figures 8, 9 and 10 show very good correlations were found in oil, water and FFA. Strong correlations between NIR-predicted values and reference data for both the calibration and validation sample sets were obtained (Table 4). The SEP match the analytical method which was used to analyse the samples.

Figure 11 shows a successful performance of the NIR On-line system in controlling water dilution at an average of $38.8 \%$ oil in crude oil and segregating the premium oil at $1.21 \%$ of FFA content. Both processes are controlled continuously and analysed simultaneously by the system.

This happens even though the control value is not in a straight line, with fluctuations still existing in the control range. The quality of the end product was found to be within the acceptance limit according to the specification for all the control parameters.

Good dilution will produce a lower oil loss, resulting in an effective separation in the clarification process. Dilution rate might not be the same especially when the number of presses in operation varied with the availability of the digested fruits for pressing. In such cases, the water dilution valve has to be regulated to adjust to the new flow requirements, but in actual practice, most mills do not alter dilution control with widely varying mill throughputs. Based on the operation scenario during the low feed rate, the crude oil is often over diluted, resulting in increased oil losses and huge amount of effluent produced.

Crude oil dilution is needed to reduce the oil viscosity. It is an important aspect of oil recovery 
TABLE 4. SUMMARY OF CALIBRATION DEVELOPED USING USING NIR-ONLINE ANALYSER

\begin{tabular}{|c|c|c|c|c|c|c|c|c|}
\hline \multirow{2}{*}{ Product name } & \multirow{2}{*}{ Sample Number } & \multirow{2}{*}{ Parameters } & \multicolumn{2}{|c|}{ Range } & \multirow{2}{*}{$R^{2}$} & \multirow{2}{*}{ SEC } & \multirow{2}{*}{ SEP } & \multirow{2}{*}{$R^{2}$} \\
\hline & & & Min & Max & & & & \\
\hline \multirow{3}{*}{ Crude palm oil } & 144 & oil & 15.28 & 50.22 & 0.881 & 3.25 & 2.94 & 0.906 \\
\hline & 187 & FFA & 0.8 & 1.75 & 0.947 & 0.05 & 0.03 & 0.939 \\
\hline & 155 & moisture & 10.7 & 40.09 & 0.854 & 2.41 & 2.87 & 0.898 \\
\hline
\end{tabular}

Note: SEC - Standard error of calibration.

SEP - Standard error of prediction.

$\mathrm{R}^{2}$ - Coefficient of determination.

$\mathrm{R}^{2}$ - Coefficient of validation.

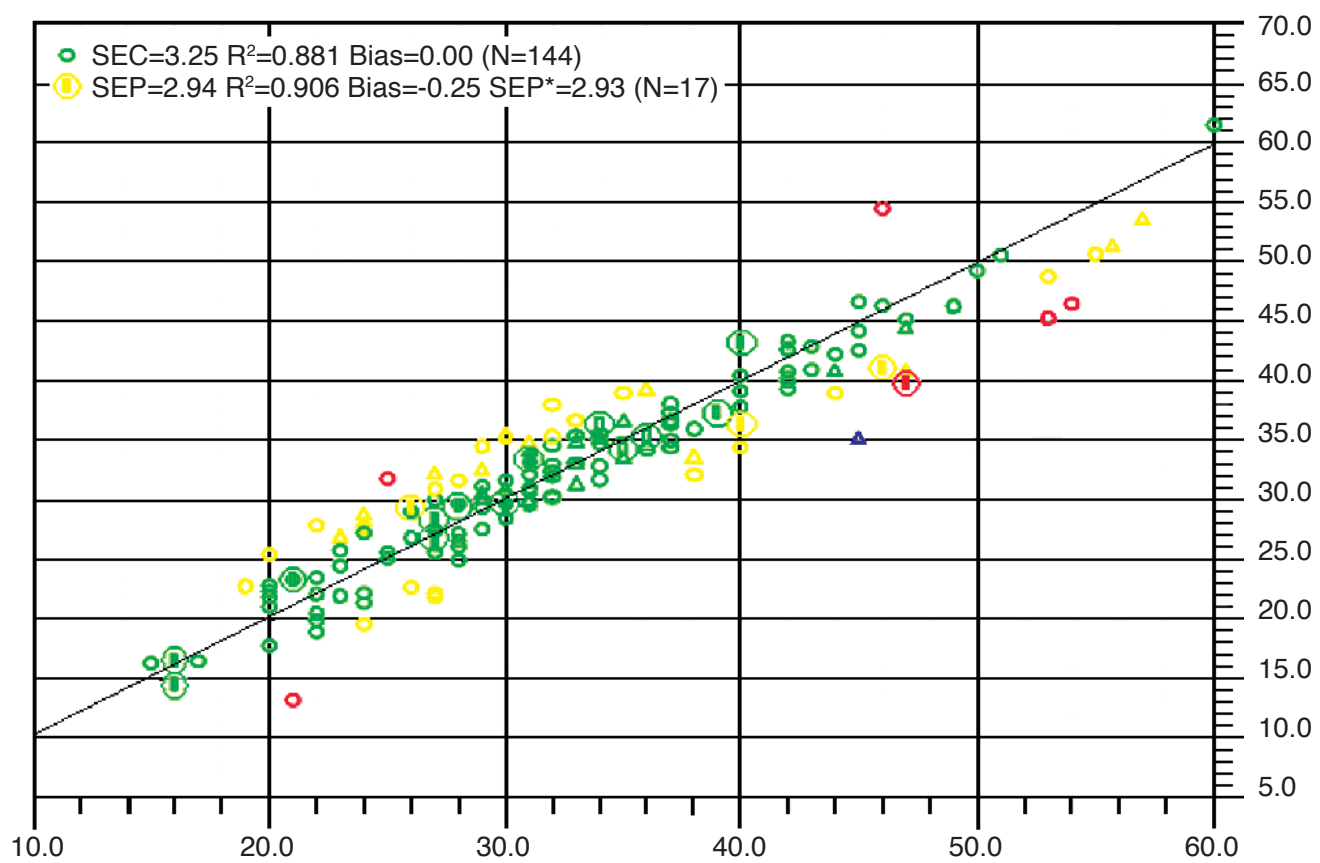

Figure 8. Near infrared (NIR) calibration curves for oil content in crude palm oil.

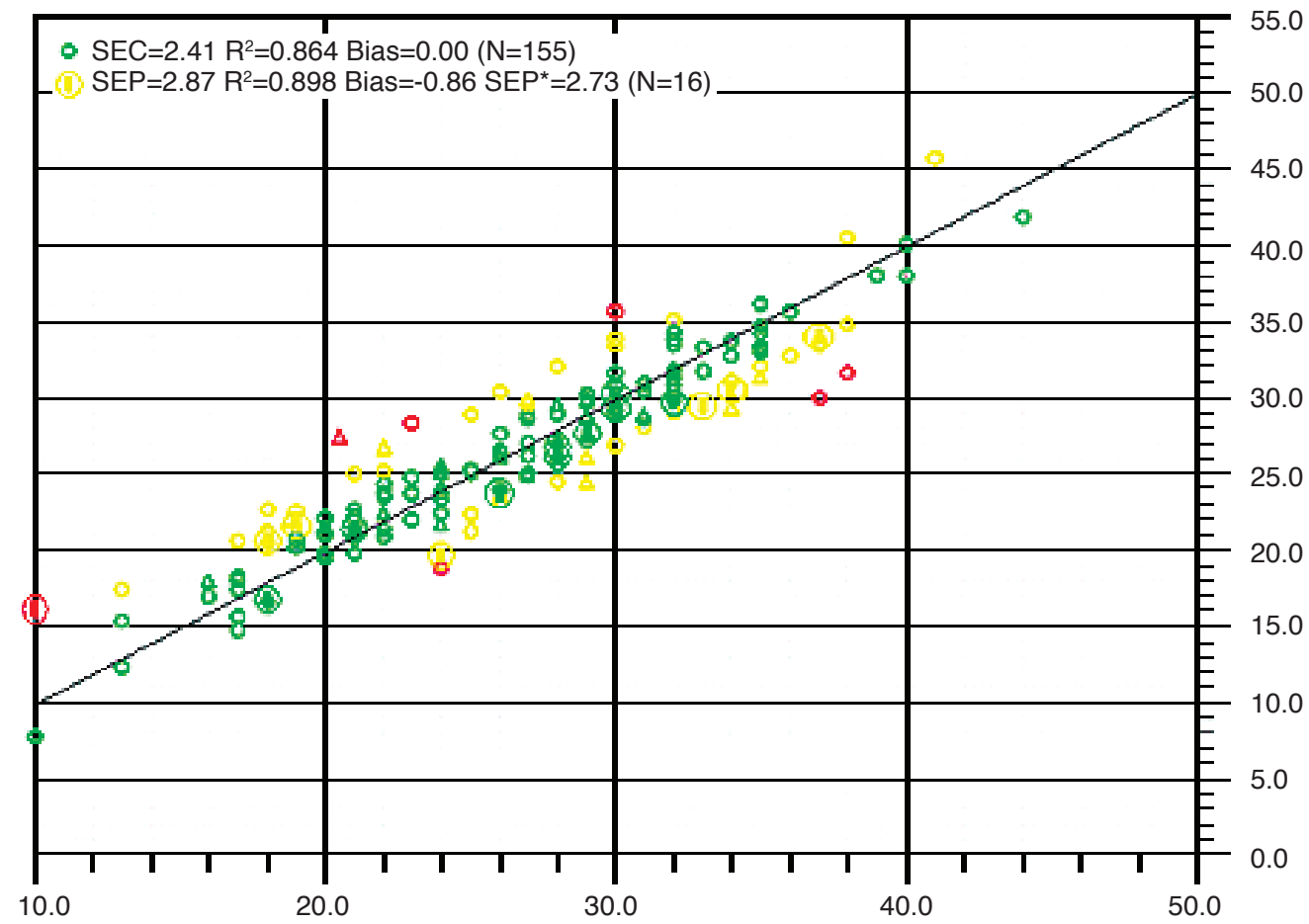

Figure 9. Near infrared (NIR) calibration curves for water content in crude palm oil. 


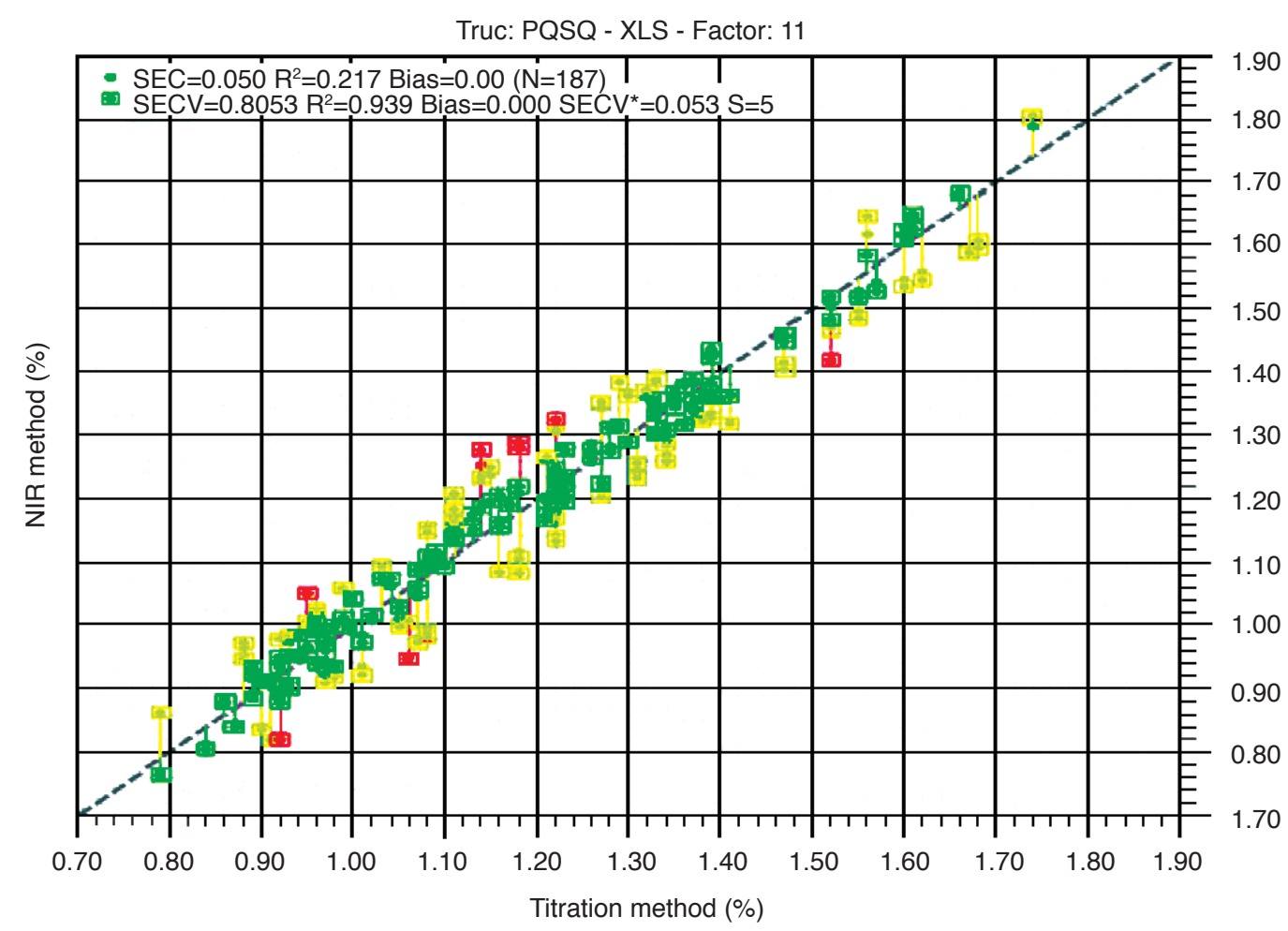

Figure 10. Near infrared (NIR) calibration curves for free fatty acid (FFA) in crude palm oil.

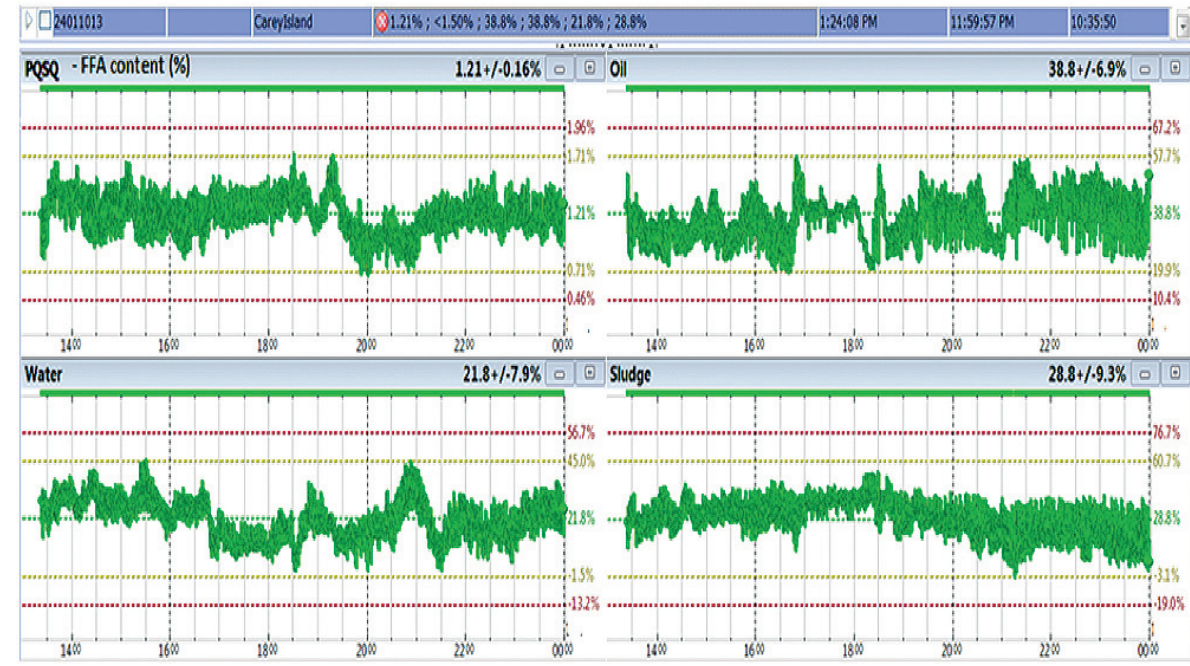

Figure 11. Near infrared (NIR) spectrum for oil, free fatty acid (FFA) and water content in crude palm oil.

and it also greatly affects the settling time. The speed of sedimentation is governed by Stoke's Law, which is applicable to particles of any dimension.

The law is as under:

$$
\mathrm{V}=\frac{\mathrm{gD}^{2}\left(\mathrm{~d}_{2}-\mathrm{d}_{1}\right)}{18 \mathrm{\eta}}
$$

where,

$$
\begin{aligned}
& \mathrm{V}=\text { speed of sedimentation } \\
& \mathrm{g}=\text { acceleration of gravity } \\
& \mathrm{D}=\text { diameter of the particles }
\end{aligned}
$$

$\mathrm{d}_{1}, \mathrm{~d}_{2}=$ densities of two media

$\eta=$ viscosity of medium
The equation shows that the final speed is directly proportional to the square of the particle diameter, difference in particles density and inversely to the viscosity. It seems that a close relationship exist between the viscosity of crude oil and rate of settling.

\section{CONCLUSION}

The development of an automatic dilution control could result in an improved efficiency in the clarifier 
process. The system gives consistent dilution at an average of $39 \%$ to $40 \%$ for any crop season or in the situation of any additional presses taken out or added to the process line based on the availability of digested crops.

The introduction of NIR in the crude oil pipe in a mill shows the obvious advantages of using NIR technology for process control. The increased yield, improved product quality and the lower product testing costs are some of the benefits that the industry has gained by the online NIR technology. Thus, NIR technology can be applied in a palm oil mill for the online measurement of multiple constituents which proves to be successful in controlling the water dilution and to effectively monitor the FFA content for the simultaneous segregation of premium oil during the palm oil process.

\section{ACKNOWLEDGEMENT}

The authors would like to thank the Director-General of MPOB for permission to publish this article. Special thanks also are recorded to Sime Darby for providing the mill facilities in Carey Island, Klang, Selangor and Zaid Yasir for the technical assistance.

\section{REFERENCES}

ABIGOR, D R; OPOKU, R A; OPUTE, F I and OSAGIE, A U (1985). Partial purification and some properties of the lipase present in oil palm (Elaeis guineensis) mesocarp. J. Sci. Food Agric., 36: 599-606.

BURNS DONALD, A and CIURCZAK EMIL, W (2008). Handbook of Near-infrared Analysis. Third edition. Taylor \& Francis Group (CRC Press), USA.

CHE MAN, Y B and MOH, M H (1998). Determination of free fatty acids in palm oil by nearinfrared reflectance spectroscopy. J. Amer. Oil Chem. Soc., 75: 557-562.

CORLEY, R H V and THINKER, P B (2003). The Oil Palm. Blackwell, USA. p. 450-471.

HENDERSON, J and OSBORNE, D J (1991). Lipase activity in ripening and mature fruit of the oil palm. Stability in vivo and in vitro. Phytochemistry, 30: 10731078.

ISHWANT SINGH (2012). Introduction to crude palm oil (CPO) dilution. http://ish83.blogspot. my / 2012/

KELLNER, H (1990). Online process control with Bran Et. Luebbe infra-analyser system with samples from the beer and flour industry. Proc. of the $3^{\text {rd }}$
International Conference on near infrared. Agricultural Research Center, Gembloux, Belim. p. 21-28.

LIM, K H and WHITING, D (1976). The influence of the non-newtonian behavior of crude palm oil on the design of clarification station equipment. Malaysian International Symposium On Palm Oil Processing \& Marketing.

MAYCOCK, J H (1987). Palm Oil Factory Process Handbook Part 1. PORIM, Bangi.

MENON, N R (2009). Clarification station operation. Palm Oil Engineering Bulletin Issue No. 93: 15-18.

MENON, N R (2008). Mongana basics: Part 10 - clarification of crude oil. Palm Oil Engineering Bulletin Issue No. 85: 39-44.

MONGANA REPORT (1955). Research on production \& storage of palm oil. Institute of Scientific Research in Industry and Agriculture. (IRSIA), Congo.

NICHOLAS, B H LIM and TIONG, K H (1988). Control of crude oil dilution in palm oil mills. $J$. Amer. Oil Chem. Soc., 65: 1953-1958.

NGANDOEBONGUE, G F; DHOUIB, R; CARRIERE, F; AMVAM ZOLLO, P H and ARONDEL, V (2006). Assaying lipase activity from oil palm fruit (Elaeis guineensis Jacq.) mesocarp. Plant Physiol. Biochem., 44: 611-617.

SAAD, B; LING, C W; JAB, M S; LIM, B P; ALI, A S $\mathrm{M}$ and WAI, D T (2006). Determination of free fatty acids in palm oil samples using non-aqueous flow injection titrimetric method. Food Chemistry, 102: 1407-1414.

SAMBANTHAMURTHI, R; O, K C and PARMAN, S H (1995). Factors affecting lipase activity in Elaeis guineensis mesocarp. Plant Physiol. Biochem., 33: 353359.

SELMAN, J D (1989). Process Monitoring and Control Online in the Food Industry. Campden Food and Drink Research Association, Gloucestershire, United Kingdom.

STORK, G (1960). Stork Palmoil Review. Gebr. Stork \& Co's Apparatenfabriek N.V. Amsterdam.

VACCARI, G; MANTOVANI, G and SGUALDINO, G (1990). The development of near-infrared (NIR) technique online in the sugar factory. Sugar J. p 4-8.

WHEELER, O H (1959). Near infrared spectra of organic compounds. Chem. Rev., 59: 629-666. 